\title{
Design and Application of Information Incentive Mechanism in Operation of Logistics Information Platform
}

\author{
Huoquan Chen \\ Quanzhou Normal University, Quanzhou, Fujian, China
}

\begin{abstract}
:
With development of 5G, information economy era marked by IoT has come rapidly and it is the objective always pursued by logistics industry to improve informatization level. During the process of logistics informatization, all levels of governments and enterprises have taken construction of public logistics information level as the main direction of logistics informatization investment. How to build a set of effective information incentive mechanism is the joint pursuit of many logistics information platform administrators. On the basis of principal-agent model, information incentive mechanism is designed in the Paper. At the same time, necessary analysis of information incentive factors is carried out. The research indicates that, with traditional incentive measures, logistics information platform administrators can better stimulate logistics information providers and improve precision of logistics information by virtue of information incentive measures; during the process of informatization, logistics information platform administrators also need to build a supervision system on the basis of certain punitive measures.
\end{abstract}

Keywords: Logistics informatization; Principal-agent model; Information incentive

\section{INTRODUCTION}

With development of 5G technology, information economy era marked by IoT has come rapidly and the state has made more efforts in investment of logistics informatization ${ }^{[1]}$. The management information system and public logistics information platform of logistics enterprises are main contents for investment and construction of logistics informatization. During the "13th Five-Year Plan" period, many public logistics information platforms had been built in many places. However, administrators of these public logistics information platforms were too superficial and focused on construction and neglected operation ${ }^{[2]}$.

As for the logistics information platform, the capacity to acquire, discriminate, analyze and 
transmit information constitutes the core competitiveness ${ }^{[3]}$. One of key factors to decide information precision is incentive degree of personnel or organization responsible for information extraction, transmission and processing. Hence, logistics information platform administrators need to build a performance measurement mechanism suitable for their own characteristics to implement the information incentive for logistics information providers ${ }^{[4]}$.

\section{DESIGN OF INFORMATION INCENTIVE MECHANISM IN LOGISTICS INFORMATIZATION}

The design of incentive mechanism for logistics information providers by the logistics information platform administrators can be regarded as the game process between the logistics information platform administrators and the logistics information providers ${ }^{[5]}$. The actions and decisions of economic activity subjects "rational people" will have mutual effect. The utility function of one subject may be influenced by other behavior subjects, so as to adjust its own actions and decisions, and affect the decisions and equilibrium of others at the same time.

Incentive and restraint are dialectically unified and inseparable. Therefore, the establishment of logistics information incentive mechanism must be based on the establishment of corresponding management control mechanism, and the latter is the core problem of logistics information incentive mechanism ${ }^{[6-7]}$. The logistics information platform administrators must optimize the assessment and supervision system and give corresponding punishment to the non-compliant behaviors. At the same time, the incentives to logistics information providers are also very important. The needs of logistics information providers can be roughly divided into material and non-material needs, so incentives can be divided into material and non-material incentives, which jointly affect the behavior of logistics information providers and stimulate their efforts $^{[8-9]}$.

\subsection{Hypotheses}

Each item of work for logistics information providers is divided into two tasks. It is assumed that the logistics information providers must divide their efforts into two tasks A and B to finish each item of work for simply research, in which A represents the effort to provide direct quantity and quality of logistics information, B represents the effort of logistics information sharing and collaborative efforts with other logistics information providers. In addition, the effort level of A is $a_{i}^{(1)}$, and the effort level of B is $a_{i}^{(2)}$, making $a_{i}=\left(a_{i}^{(1)}, a_{i}^{(2)}\right)$. Output function $\pi_{i}=a_{i}+\varepsilon$, and $\varepsilon \sim \mathrm{N}(0, \Sigma)$ represents exogenous uncertain factors, where 


$$
\sum=\left(\begin{array}{cc}
\delta_{11}^{2} & r \delta_{12} \\
r \delta_{12} & r^{2} \delta_{22}^{2}
\end{array}\right)
$$

Here $r(0 \leq r \leq 1)$ is the information incentive factor, representing the information incentive of logistics information platform administrators to logistics information providers who are willing to share and work cooperatively. According to the form of above variance matrix, the smaller the information incentive factor is, the higher the information incentive intensity is. Information incentive is of great importance because it will enhance the information communication between logistics information platform administrators and logistics information providers ${ }^{[10]}$.

It is assumed that both logistics information platform administrators and logistics information providers are rational, and logistics information platform administrators pursue utility maximization, which is manifested as their economic interests maximization. Logistics information providers pursue the personal income maximization. Logistics information providers can benefit from effort or low effort (i.e., slacking).The effort level of logistics information providers can be improved by the increase of incentive of logistics information platform administrators ${ }^{[11]}$.

Logistics information platform administrators have multiple incentives, and the corresponding effort forms of logistics information providers are also divers ${ }^{[12]}$. It is assumed that logistics information platform administrators motivate logistics information providers to work hard through two ways of monetary and non-monetary incentives. Monetary incentives mainly refer to material incentives, which are used to motivate logistics information providers in the form of allowances, subsidies, rewards, welfare funds, and etc. Non-monetary incentives mainly refer to spiritual rewards, such as certificates of merit, certificates, rises in rank, promotion and so on. Logistics information providers have two kinds of efforts, namely monetary efforts En and non-monetary efforts Em. For simple analysis, it is assumed that the benefits from both efforts can be monetized, that is, can be measured by currency (i.e. substitution of mind to material); The incentive coefficients of the enterprise to the two kinds of efforts are $\xi_{n}$ and $\xi_{m}$ respectively, that is, the benefits brought by the two efforts to logistics information providers are $\xi_{n} E_{n}$ and $\xi_{m} E_{m}$ respectively. The effort cost of logistics information providers is $C=1 / 2\left(\theta_{n} E_{n}^{2}+\theta_{m} E_{m}^{2}\right), \theta_{n}$ and $\theta_{m}$ are cost coefficients for two kinds of efforts, for simple analysis, $\theta_{n}=\theta_{m}=\theta$ can be assumed, and we can get $C=\theta\left(E_{m}^{2}+E_{n}^{2}\right) / 2$. 
Output $\mathrm{Q}$ of the logistics information platform administrators is determined by the two efforts of the logistics information providers. The form of Cobb-Douglas production function is adopted here. We assume the following model $Q=K E_{n}^{\lambda} E_{m}^{1-\lambda}(0<\lambda<1)$. For simple analysis, $\mathrm{K}=1$ is assumed, then $Q=E_{n}^{\lambda} E_{m}^{1-\lambda}$. In the formula, $\lambda$ represents the importance level of monetary efforts in the output of logistics information platform, that is, the preference of logistics information platform to monetary efforts; $1-\lambda$ represents the importance level of non-monetary efforts in the output of logistics information platform. $\lambda>0.5$ indicates that the preference of logistics information platform to monetary efforts is greater than that to non-monetary efforts, and vice versa.

Supervision input of logistics information platform administrators: namely, It is supervision cost, and p is efficiency of supervision. When logistics information providers are in low effort, the probability that logistics information platform administrators find logistics information providers in low effort is $p$, and obviously $1-p$ is the probability that logistics information providers are not found for slacking. Here, $\mathrm{P}$ is determined by the cost and efficiency of supervision, that is, $\mathrm{P}=\mathrm{P}(\mathrm{I}, \mathrm{p})$, and $\partial P / \partial I>0, \partial P / \partial p>0$. $\mathrm{d}$ is the punishment given to logistics information providers by the logistics information platform administrators after finding their slacking.

\subsection{Model}

Logistics information platform administrator determines the payment to the logistics information provider according to the observation of the logistics information provider's efforts, that is, to determine the incentive coefficient $\xi_{n}$ and $\xi_{m}$; based on the incentive coefficient, logistics information provider determines its own efforts. In accordance with the hypothesis above, it clearly shows that, by determining the incentive coefficient related to efforts, the logistics information platform administrator stimulates efforts of the logistics information provider. Thus, the objective utility of the enterprise is:

$$
\max \left\{\xi_{n}, \xi_{m}\right\}^{U=E_{n}^{\lambda} E^{1-\lambda}{ }_{m}-1-W_{0}-\xi_{n} E_{n}-\xi_{m} E_{m}}
$$

Assuming that the basic income (i.e. fixed income) of logistics information provider is WO, the objective utility of the logistics information provider is: 


$$
\max \left\{E_{n}, E_{m}\right\}^{W=W_{0}+\xi_{n} E_{n}+\xi_{m} E_{m}-1 / 2 \theta\left(E_{n}^{2}+E_{m}^{2}\right)}
$$

Assuming that $\mathrm{W}$ is the minimum retained income, which is determined by the social average level. Therefore, participation constraint (IR) of the logistics information provider is:

$$
W=W_{0}+\xi_{n} E_{n}+\xi_{m} E_{m}-C \geq \bar{W}
$$

En' refers to the low monetary efforts of logistics information providers and Em' refers to non-monetary efforts of logistics information providers. If the logistics information provider is in a state of low efforts and fails to be noticed by the logistics information platform administrator (probability is 1-P), then the income of the logistics information provider is showed as $W_{O}+\xi_{n} E_{n}+\xi_{m} E_{m}-C^{\prime}$, among which $C^{\prime}=\theta\left(E_{n}^{\prime 2}+E_{m}^{\prime 2}\right)$, that means the cost of the logistics information provider in the state of low efforts. Relatively, the income of the logistics information provider, after logistics information platform administrator notice that logistics information provider is in a state of low efforts, is referred to as $W_{O}+\xi_{n} E_{n}+\xi_{m} E_{m}-C^{\prime}-\mathrm{d}$. Thus, we can obtain incentive compatibility constraint which is:

$$
W_{o}+\xi_{n} E_{n}+\xi_{m} E_{m}-C \geq(1-P)\left(W_{o}+\xi_{n} E_{n}+\xi_{m} E_{m}-C^{\prime}\right)+P\left(W_{o}+\xi_{n} E_{n}^{\prime}+\xi_{m} E_{m}^{\prime}-C^{\prime}-d\right)^{\Theta}
$$

After the first-order partial derivatives of formula (2) is calculated, $E_{n}=\xi_{n} / \theta$ as well as $E_{m}=\xi_{m} / \theta$ can be obtained. At this time, the problem of logistics information platform administrator is altered to:

$$
\max \left\{\xi_{n}, \xi_{m}\right\}^{U=E_{n}^{\lambda} E^{1-\lambda}{ }_{m}-1-W_{0}-\xi_{n} E_{n}-\xi_{m} E_{m}}
$$

\section{ANALYSIS OF INFORMATION INCENTIVE FACTOR BASED ON MODEL}

Formulas, $\partial E_{n} / \partial \xi_{n}=1 / \theta>0$ and $\partial E_{m} / \partial \xi_{m}=1 / \theta>0$, are easy to be obtained. Thus, as the incentive coefficient increases, efforts of logistics information providers increase accordingly. That is to say, the more reward logistics information provider gets from logistics information platform administrator, the greater efforts logistics information providers are willing to pay. Formulas, $\partial E_{n} / \partial \theta=-\xi_{n} / \theta^{2}<0$ and $\partial E_{m} / \partial \theta=-\xi_{m} / \theta^{2}<0$, are also clearly to be 
obtained, showing that efforts of logistics information providers are inversely proportional to the cost coefficient of efforts. Adequate understanding and respect shall be given to logistics information providers for their contribution by logistics information platform administrators who shall also create an appropriate ecological environment for logistics information provider, which means reducing the cost of logistics information providers ${ }^{[13]}$.

$$
E_{n}=\xi_{n} / \theta \text { and } E_{m}=\xi_{m} / \theta \text { are substituted into the formula (4) and the following formula }
$$

can be obtained:

$$
U=\frac{\left(\xi_{n}\right)^{\lambda}\left(\xi_{m}\right)^{1-\lambda}}{\theta}-\frac{\xi_{n}^{2}}{\theta}-\frac{\xi_{m}^{2}}{\theta}-W_{0}-1
$$

After the first-order partial derivatives of formula (5) are calculated, the following formulas can be obtained:

$$
\begin{gathered}
\xi_{n}^{*}=\frac{\lambda}{2}\left\{\sqrt{\frac{\lambda}{1-\lambda}}\right\}^{\lambda-1} \\
\xi_{m}^{*}=\frac{\lambda}{2}\left\{\sqrt{\frac{\lambda}{1-\lambda}}\right\}^{\lambda-2}
\end{gathered}
$$

After substitution, the optimal solution can be obtained as follows:

$$
\begin{aligned}
& E_{n}^{*}=\frac{\xi_{n}^{*}}{\theta}=\frac{\lambda}{2 \theta}\left\{\sqrt{\frac{\lambda}{1-\lambda}}\right\}^{\lambda-1} \\
& E_{m}^{*}=\frac{\xi_{m}^{*}}{\theta}=\frac{\lambda}{2 \theta}\left\{\sqrt{\frac{\lambda}{1-\lambda}}\right\}^{\lambda-1}
\end{aligned}
$$

It can be see that, under equilibrium state, the incentive coefficient of the logistics information platform administrator is a function of $\lambda$, the preference of monetary efforts by logistics information platform administrator. This shows that the incentive mode of logistics information platform administrators to logistics information providers is related to which form of efforts logistics information platform administrators prefer. While, under equilibrium state, effort of logistics information providers is a function of $\lambda$, the preference of logistics 
information platform administrator, and $\theta$, the cost coefficient of efforts, which determine the effort level of logistics information provider.

After formula (6), formula (7), formula (8) and formula (9) are substituted into formula (1) and formula (2), utilities of logistics information platform administrators and logistics information providers under equilibrium state are relatively as follows:

$$
U^{*}=\frac{\lambda}{4 \theta}\left\{\frac{\lambda}{1-\lambda}\right\}^{\lambda-1}-W_{0}-1 \text { and } W^{*}=W_{0}+\frac{\lambda}{8 \theta}\left\{\frac{\lambda}{1-\lambda}\right\}^{\lambda-1}
$$

The following formulas can also be obtained:

$$
\begin{aligned}
\frac{\partial U^{*}}{\partial \lambda} & =\frac{\lambda}{4 \theta}\left\{\frac{\lambda}{1-\lambda}\right\}^{\lambda-1} \ln \frac{\lambda}{1-\lambda} \\
\frac{\partial \mathrm{W}^{*}}{\partial \lambda} & =\frac{\lambda}{8 \theta}\left\{\frac{\lambda}{1-\lambda}\right\}^{\lambda-1} \ln \frac{\lambda}{1-\lambda}
\end{aligned}
$$

Formula (10) and Formula (11) indicate that when $\lambda>0.5, \ln _{1-\lambda}>0$ and then $\partial U^{*} / \partial \lambda>0$ as well as $\partial W^{*} / \partial \lambda>0$ can be obtained. This shows that when preference of monetary incentive is greater than non-monetary incentive, the utility of both logistics information platform administrators and logistics information providers increases with increase of $\lambda$, preference of En, monetary efforts, by logistics information platform administrator. In other words, logistics information providers would prefer logistics information platform administrators. That is, if the logistics information platform administrators attach more importance to monetary incentive, logistics information providers will be more willing to pay monetary efforts to get rewards. On the contrary, $\lambda<0.5$ indicates that logistics information platform administrators prefer non-monetary incentive, and logistics information providers are more willing to pay monetary efforts at this time.

Here it should be noticed that many logistics information platform administrators focus on material incentive, namely monetary incentive. However, people have various needs, and spiritual incentive can also play an important role in the utility of logistics information platform administrators $^{[14]}$. It is not completely their economic interests that affect the behavior of logistics information provider. Therefore, logistics information platform administrators should not only consider issues from the material aspect when designing incentive mechanism, 
otherwise it will be quite one-sided. What logistics information providers need is not only material incentive, but also various characteristic spiritual incentives ${ }^{[15]}$. It should also be noticed that non-monetary incentive can effectively reduce the cost of logistics information platform administrators, promote the enthusiasm of logistics information providers, and advance the utility of logistics information platform administrators at a relatively low cost.

Further observation on the utility function of logistics information platform administrators $U=E_{n}^{\lambda} E_{m}^{1-\lambda}-I-W_{O}-\xi_{n} E_{n}-\xi_{m} E_{m}$ easily shows that:

$$
\begin{array}{ll}
\frac{\partial U}{\partial E_{n}}=\lambda E_{n}^{\lambda-1} E_{m}^{1-\lambda}-\xi_{n} & \frac{\partial U}{\partial E_{m}}=(1-\lambda) E_{n}^{\lambda} E_{m}^{-\lambda}-\xi_{m} \\
\frac{\partial U}{\partial E_{n}}=\lambda E_{n}^{\lambda-1} E_{m}^{1-\lambda}-\xi_{n} & \text { and } \frac{\partial U}{\partial E_{m}}=(1-\lambda) E_{n}^{\lambda} E_{m}^{-\lambda}-\xi_{m}
\end{array}
$$

Logistics information platform administrators hope that $\partial U / \partial E_{n}>0$ and $\partial U / \partial E_{m}>0$ can be obtained so that the utility of logistics information platform administrators will increase with increase of logistics information provider's efforts. Therefore, we can draw derivations as follows:

$$
\begin{gathered}
\frac{\partial U}{\partial E_{n}}=\lambda E_{n}^{\lambda-1} E_{m}^{1-\lambda}-\xi>0 \Rightarrow\left\{\frac{E_{n}}{E_{m}}\right\}^{\lambda-1}>\frac{\xi_{n}}{\lambda}(>0) \\
\frac{\partial U}{\partial E_{m}}=(1-\lambda) E_{n}^{\lambda 1} E_{m}^{-\lambda}-\xi_{m}>0 \Rightarrow\left\{\frac{E_{n}}{E_{m}}\right\}^{\lambda}>\frac{\xi_{m}}{1-\lambda}(>0)
\end{gathered}
$$

Using formula (13) to divide formula (12), we can obtain the following:

$$
\Sigma=\left(\begin{array}{cc}
\delta_{11}^{2} & r \delta_{12} \\
r \delta_{12} & r^{2} \delta_{22}^{2}
\end{array}\right) \frac{E_{n}}{E_{m}}>\frac{\lambda / 1-\lambda}{\xi_{n} / \xi_{m}}
$$

In the formula above, $\lambda / 1-\lambda$ refers to the proportion between preference of monetary efforts and preference of non-monetary efforts by logistics information platform administrator, and $\xi_{n} / \xi_{m}$ refers to the proportion of earning made through two kinds of efforts, which shall be in accordance with the formula (14) so that the utility of logistics information platform administrators will increase with increase of logistics information providers' monetary efforts and non-monetary efforts. Two formulas can also be obtained: 


$$
\begin{aligned}
& \frac{\partial^{2} U}{\partial E_{n}^{2}}=\lambda(\lambda-1) E_{n}^{\lambda-2} E_{m}^{1-\lambda}(<0) \text { and } \frac{\partial^{2} U}{\partial E_{m}^{2}}=-\lambda(1-\lambda) E_{m}^{-\lambda-1} E_{n}^{\lambda}(<0) \\
& \frac{\partial^{2} U}{\partial E_{n}^{2}}=\lambda(\lambda-1) E_{n}^{\lambda-2} E_{m}^{1-\lambda}(<0) \text { and } \frac{\partial^{2} U}{\partial E_{m}^{2}}=-\lambda(1-\lambda) E_{m}^{-\lambda-1} E_{n}^{\lambda}(<0)
\end{aligned}
$$

It shows that the growth speed of utility of logistics information platform administrators gradually slows down as efforts of logistics information providers are increasing. It is in line with the utility function of logistics information platform administrator.

$$
\begin{aligned}
& W_{o}+\xi_{n} E_{n}+\xi_{m} E_{m}-C \geq(1-P)\left(W_{o}+\xi_{n} E_{n}+\xi_{m} E_{m}-C^{\prime}\right)+P\left(W_{o}+\xi_{n} E_{n}{ }^{\prime}+\xi_{m} E_{m}{ }^{\prime}-C^{\prime}-d\right) \\
& \text { After rearrangement: }-C \geq-C^{\prime}-P \xi_{n}\left(E_{n}-E_{n}^{\prime}\right)-P \xi_{m}\left(E_{m}-E_{m}^{\prime}\right)-P d \text {, namely } \\
& \Delta C \leq P\left(\xi_{n} \Delta E_{n}+\xi_{m} \Delta E_{m}+d\right)
\end{aligned}
$$

Where:

$$
\Delta C=C-C^{\prime}, \Delta E_{n}=E_{n}-E_{n}^{\prime}, \Delta E_{m}=E_{m}-E_{m}^{\prime}
$$

$\Delta C$ represents effort costs that are saved under low efforts of logistics information providers, which can be regarded as advantages brought by low efforts. $\Delta E_{n}$ and $\Delta E_{m}$ are respectively varying inexertion degrees of logistics information providers. Thus, $\xi_{n} \Delta E_{n}$ and $\xi_{m} \Delta E_{m}$ are lost profits under low efforts of logistics information providers. $\xi_{n} \Delta E_{n}+\xi_{m} \Delta E_{m}$ can be marked as $\Delta Y$, then the formula can turn to $P \geq \Delta C /(\Delta Y+d)$. In this way, $\Delta C$ can be regarded as advantages brought by low efforts while $\Delta Y+d$ is the loss under low efforts. It can be seen that $\mathrm{P}$ is at least required to equal $\Delta C /(\Delta Y+d)$ if it is needed that logistics information providers shall not work under low efforts, that is, the probability that logistics information platform administrators find logistics information providers are under low efforts is at least the ratio of benefits and loss when logistics information providers are under low efforts. Actually $\mathrm{P}$ cannot be greater than 1 because if $\mathrm{P}$ is greater than 1 , it is significantly found that $\Delta C$ is greater than $\Delta Y+d$, which is to say that the benefits under low efforts are greater than that under hard work. If so, who will work hard? Therefore, it is not allowed for logistics information platform administrators. Seeing that logistics information platform administrators cannot find all low-effort phenomena, if effective monitoring also works when $\mathrm{P}$ is lower, through the formula it 
is found that $\mathrm{P}$ can be allowed to be less as $\mathrm{b}$ is more. That is to say, logistics information platform administrators shall strengthen punishment if they want to reduce the price of low monitoring.

It is can be seen from formula (3) that the right side of formula is expected utilities when logistics information providers are under low efforts, which is represented by $\mathrm{E}(\mathrm{W})$. It is easy to find that: $\partial E(W) / \partial p<0, \partial E(W) / \partial I<0, \partial E(W) / \partial d<0$. It illustrates that $\mathrm{E}(\mathrm{W})$ is a decreasing function related to $\mathrm{p}, 1, \mathrm{~d}$, which explicitly suggests that logistics information platform administrators try to improve the efficiency of this part and strengthen the investigation together punishment through increase investment in monitoring and supervision, reducing the expected profits of those logistics information providers who are under inexertion. Hence, in this way, logistics information providers can be forced to increase their efforts degree in a bid to gain more profits. It is proved by the model that logistics information platform administrators must improve supervision mechanisms and they need not only incentive factors but also perfect supervision mechanisms ${ }^{[16]}$.

\section{CONCLUSION}

The use of monetary incentive by logistics information platform administrators will enable information incentive costs to increase and subsequently influence utilities of logistics information platforms. Furthermore, this situation may produce side effects: force logistics information providers to work simply for gaining bonuses. Thus, this kind of incentive way does not boost logistics information providers' passion from the subjectivity. From the above model, it is seen that only through non-monetary incentives can logistics information platform administrators effectively stimulate logistics information providers ${ }^{[17]}$.

From the analysis of model, there is a great correlation between the preference of logistics information platform administrators on incentive mode together with effort costs of logistics information providers and the utility change as logistics information platform administrators and logistics information providers are under mutual balance while the income of the logistics information providers has no impact on their effort levels, which is largely because the effort levels of the logistics information providers have no impact on their fixed income ${ }^{[18]}$. Thus, with traditional incentive measures, logistics information platform administrators can better stimulate logistics information providers. Finally, logistics information platform administrators also need to build a supervision system on the basis of certain punitive measures.

\section{ACKNOWLEDGEMENTS}


Soft Science Foundation of China Fujian Provincial Department of Science \& Technology: (2014R0013).

\section{REFERENCES}

[1] Gao F, Sun W, Zhu H T (2021) Intelligent transformation of logistics industry based on 5G technology. Technology and Market 28(08):103+105

[2] Xu L (2021) Research on the Development Status and Problems of Modern Logistics Informatization. Business Economy 03:83-85+97

[3] Dong L, Liu K (2006) Research on Regional Logistics Information Platform Construction. Logistics Technology 04:86-88

[4] Lin Z X (2021) Enterprise incentive mechanism, how to achieve efficiency improvement. Human Resources 18:70-71

[5] Yao Z Z, Zhang B (2021) Evolutionary Game Analysis of Users' Participation Behavior in Online Health Community under Incentive Mechanism. Information Science 39(08):149-155+163

[6] Wu Yun (1996) The historical development and its enlightenment of the western incentive theory. Study \& Exploration 6:88-93

[7] Diane Carmeliza N. Cuaresma and Justine Angeli L. Saquing and Vincent Paulo M. TY (2019) Determining Crop Insurance Participation in Laguna, Philippines Using Subsidy and Asymmetric Information Incentives. International Journal of Environmental and Rural Development $8(1): 163-168$

[8] Yuan P, Xiong Y, Li Y et al (2017) Explore the impact of information incentive distance on product design thinking based on EEG alpha wave activity. Journal of Mechanical Engineering (53) 15:40-48

[9] Fumuro T, Matsuhashi M, Miyazaki T, et al (2015) Alpha-band desynchronization in human parietal area during reach planning. Clinical Neurophysiology 126(4):756-762

[10] Li Zhibin (2011) Design of the third-party logistics service innovation mechanism based on the game perspective. Seeker 04:36-38

[11] Ni Y R (2019) The Importance of Incentive Mechanism in Modern Enterprise Human Resources Management. China Circulation Economy 34:91-93

[12] Jiang L, Liu Z C (2020) On the Incentive Mechanism of Modern Enterprise Culture in Human Resource Management. Enterprise Science And Technology \& Development 09:171-172+175

[13] Wang X M, Li S M, Yang H G, Shen Y (2011) Study on dynamic incentive contracts in telecom business innovation with win-win consideration. Journal of Systems Engineering 26(05):671-678

[14] Bu N Y (2019) Discussion on the Application of Incentive Mechanism in Enterprise Human Resources Management. Manager 'Journal 04:67-69

[15] Tang C F (2015) Research on the Construction of Effective Incentive Mechanism for State-owned Enterprises. Modern Economic Research 07:72-76

[16] Wu K, Zhang H Y (2016) Suoerivisory Intensity and Incentive Mechanism Based on Principal-agency Relationship. Systems Engineering 34(07):68-72

[17] Song Y (2012) Incentive Mechanism in the Salary Management of Knowledge Workers. Journal of Chongqing University of Science and Technology(Social Sciences Edition) 05:116-118 
Forest Chemicals Review

www.forestchemicalsreview.com

ISSN: 1520-0191

July-August 2021 Page No.408-419

Article History: Received: 10 May 2021 Revised: 20 June 2021 Accepted: 18 July 2021 Publication: 31 August 2021

[18] Duan Y R, Wang H R, Huo J Z (2011) Design of an Employee Incentive Mechanism based on Synergistic and Sharing Effect. Journal of Systems \& Management 20(06):641-647 